\title{
Commercial Friendships During a Pandemic
}

\author{
Virgil Henry Storr ${ }^{1,2,3} \cdot$ Rachael K. Behr ${ }^{1,2,3} \cdot$ Michael R. Romero ${ }^{1,2,3}$
}

Accepted: 26 August 2021

(c) The Author(s), under exclusive licence to Springer Science+Business Media, LLC, part of Springer Nature 2021

\begin{abstract}
Although much of the nascent scholarship on COVID-19 has highlighted the tremendous health, economic, and social consequences of the pandemic, what has been underappreciated is the loss of commercial friendships due to the pandemic. Markets are social spaces where individuals can meet and form meaningful connections. But, because many market interactions that would have taken place in person before the pandemic moved remote and online, or were cancelled altogether, the COVID19 pandemic has limited the ability of market participants to form and maintain meaningful social bonds. Indeed, we argue that COVID-19 is a disruptor of the formation and continuance of these commercial relationships. Specifically, we find that throughout the COVID-19 pandemic: (1) commercial interactions have become more anonymous and less personalized; (2) the formation and maintenance of commercial friendships are hindered because of the transition to virtual platforms, which are imperfect substitutes for in person connections; (3) during lockdowns, individuals spend more time interacting with closer ties rather than weaker ties; and (4) during the pandemic commercial settings are less likely to serve as social arenas.
\end{abstract}

Keywords COVID-19 $\cdot$ Commercial friendships $\cdot$ Markets $\cdot$ Social spaces

JEL codes $\mathrm{B} 53 \cdot \mathrm{I} 1 \cdot \mathrm{O} 51 \cdot \mathrm{Z} 13$

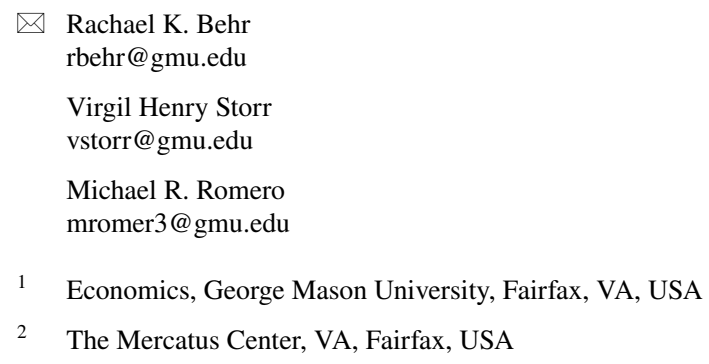




\section{Introduction}

COVID-19 has, in large part, defined 2020 and at least the first half of 2021. As of June 2021, there are over 3.5 million deaths worldwide from the novel coronavirus (Dong et al., 2021) and there are over 600,000 deaths in the United States alone (The New York Times, 2021a). The pandemic has also affected people's mental health. During the COVID-19 pandemic, the prevalence of general anxiety disorder and depression are significantly higher (Bueno-Notivol et al., 2021; Hyland et al., 2020). For instance, $77 \%$ of respondents in an ABC News/Washington Post poll done in late March of 2020 noted that their lives have been disrupted by the pandemic, while $70 \%$ reported personal stress due to COVID- 19 . Moreover, $70 \%$ were also worried that they or an immediate family member could become infected (Langer, 2020). The physical and mental health effects on infected individuals can be immense, and for many, may last for years beyond their becoming sick.

COVID-19 has also caused tremendous economic disruption. Economists have described the COVID-19 recession as the worst economic crisis since the Great Depression. The United States' GDP has taken a large hit during the pandemic. Makridis and Hartley (2020) estimated "a 5[\%] decline in real GDP growth for every one month of partial economic shutdown. Thus, the economic cost of two months of mitigation measures is $\$ 2.14$ trillion (10[\%])." The Bureau of Economic Analysis (BEA) estimated there was a 9.1\% drop in second quarter 2020 GDP (BEA, 2020). Estimates from research bank Jeffries found that large firm bankruptcies were $244 \%$ higher, year-over-year in the July-August 2020 period (Moon, 2020). In terms of unemployment, the Congressional Research Service (CRS) (2020) found that the "unemployment rate peaked at an unprecedented level, not seen since data collection started in 1948, in April 2020 (14.7\%) before declining to a still-elevated level in October (6.9\%)." And, in April of 2020, "every state and the District of Columbia reached unemployment rates greater than their highest unemployment rates during the Great Recession" (CRS, 2020).

While COVID-19 has resulted in tremendous loss of life and disrupted people's health and livelihood, it has also had a tremendous social cost. Indeed, pandemics can undermine social trust and disrupt social networks. For instance, Aassve et al. (2020) studied the deadly influenza virus of 1918-19 (the so-called "Spanish Flu") and found that "experiencing the pandemic likely had permanent consequences in terms of individuals' social trust." The authors conclude that.

failure of institutions and society to cope with the crisis (a failure whose most visible result was the widespread mortality) is what, we believe, led to significant and persistent consequences on individual's social trust-a point which ... might have some relevance for the current crisis caused by COVID-19 (Aassve et al., 2020).

They go on to describe how the "collapse of traditional networks of social support as well as with the inability of public institutions to provide adequate care and relief" is what led to large changes in trust, particularly for those who were 
infected with and survived the flu (Aassve et al., 2020). Interestingly, those in neutral countries during WWI experienced a greater negative effect of the epidemic on trust, likely because such countries had less censorship of the news, and thus these individuals had nearly complete information about the severity of the epidemic (Aassve et al., 2020).

The growing literature on the COVID-19 pandemic, however, has not yet discussed the impact of COVID-19 on commercial friendships, that is, friendships and acquaintances formed because of marketplace interactions. Markets are spaces where individuals can form deep and meaningful relationships that would otherwise be nonexistent (Storr, 2008). As Smith ([1759] 1976: 223-224) puts it,

the necessity or convenience of mutual accommodation very frequently produces a friendship not unlike that which takes place among those who are born to live in the same family. Colleagues in office, partners in trade, call one another brothers; and frequently feel towards one another as if they really were so.

Markets are not only meeting grounds where people might encounter potential friends and close acquaintances, but they also facilitate interaction in ways that develop trust. The COVID-19 pandemic has disrupted such meeting grounds and relationships, at least in places where it provided the impetus for shut-downs and closures of workplaces, schools, restaurants, gyms, and so forth. While loss of social contact has been discussed throughout the COVID-19 crisis, loss of commercial friendships has not yet been discussed in any meaningful way. We are the first, to our knowledge, to contribute to this area of study through the COVID-19 crisis.

In this paper, we argue that if one considers the market as a social space, where individuals can meet and form commercial friendships and acquaintances, then COVID-19 has necessarily disrupted such a process. We claim that people met with commercial and workplace friends much less frequently due to work-from-home measures, and that they felt they lost something of great value, despite the fact that many enjoy working from home. Our primary data to support this claim is a survey aimed at "Understanding Response and Recovery During the COVID-19 Pandemic." " Our secondary data comes from popular and academic articles attempting to understand individuals' evaluations of their market friendships and acquaintances during COVID-19. We contribute to several important literatures. First, we contribute to the literature on the market as a social space and the literature on relational work by focusing on the importance of contact, especially face-to-face interactions, in facilitating the development and maintenance of commercial friendships. Second, by focusing on the loss of commercial friendships during the COVID-19 pandemic, we add to the growing literature on the social costs of the pandemic.

\footnotetext{
1 This survey was conducted on behalf of the Mercatus Center at George Mason University in September 2020, and it surveyed 1105 individuals from the 50 United States, Washington, D.C., and Puerto Rico. The survey asked respondents about their experiences during the first few months of the COVID19 pandemic. The survey was evenly balanced demographically (e.g. 53\%-to-47\% Female-to-Male, 40\%to-32\% Democrats-to-Republicans). We will refer to this survey throughout as "our survey.".
} 
The paper proceeds as follows. Section 2 discusses how commercial relationships not only form within markets, but often rely upon markets for their survival. Then, we examine how virtual interactions often cannot replicate the face-to-face interactions that frequently take place in market spaces. Section 3 examines COVID-19 as a disruptor of these commercial friendships and is supported by survey and other evidence regarding commercial friendships and acquaintances during the COVID19 pandemic. We find that throughout the COVID-19 pandemic: 1) commercial interactions have become more anonymous and less personalized; (2) the formation and maintenance of commercial friendships are hindered because of the transition to virtual platforms, which are imperfect substitutes for in person connections; (3) during lockdowns, individuals spend more time interacting with closer ties rather than weaker ties; and (4) during the pandemic, commercial settings are less likely to serve as social arenas. In general, we argue that COVID-19 has disrupted commercial relationships, which has large consequences as people suffer large social losses and increased loneliness. Section 4 offers concluding thoughts.

\section{Markets as social spaces}

There have been several surveys conducted in recent years that speak to the importance of friendships. Pew Research Center (2018), for example, asked a series of close-ended questions to a nationally representative panel of 4,729 randomly selected U.S. adults. They found that $47 \%$ reported "spending time with friends" who provided "a great deal of meaning and fulfillment in their lives" (ibid.: 5). In a related survey of the same year Pew Research Center (ibid.: 4) asked its U.S. adult respondents "to describe in their own words... what provides them with a sense of meaning." When asked this open-ended question, 19\% mentioned friends with the majority (69\%) discussing family (ibid.). Despite this disparity between the answers to the closed- and open-ended questions, it is clear that at least for many Americans their friendships are regarded as meaningful. Similar findings are reported in the most recent World Values Survey of 2017-2020 (Haerpfer et al., 2020), wherein about $51 \%$ of Americans reported that "friends" were a "very important" aspect of their lives, while about $38 \%$ reported that "friends" were "rather important." Similar findings are reported when considering the responses from all 79 surveyed countries. Combining all survey respondents, regardless of country, about $45 \%$ reported that friends were "very important," while about 44\% reported that friends were "rather important" (ibid.).

The potential of markets to support the development and maintenance of friendships, then, is particularly important given how meaningful people generally regard their friendships. For Austrians, the market is a social process, and like other social phenomena it is constituted by the meanings its participants attach to it. As Mises put it ([1949] 2007: 312), "the market is a social body; it is the foremost social body. The market phenomena are social phenomena. They are the resultant of each individual's active contribution." Not surprisingly, then, Austrians have highlighted the personal relationships that not only form within markets but depend on markets for their cultivation, maintenance, and survival (see e.g., Chamlee-Wright, 1997, 2010; 
Storr, 2008, 2009, 2010; Chamlee-Wright and Storr, 2009, 2014; Storr et al., 2015a, b; Grube \& Storr, 2018; Storr \& Choi, 2019; Storr \& Stein, 2019). Hayek (1976: 112-113), for instance, recognized that the market is the,

'cash-nexus' which holds the Great Society together, ... the great ideal of unity of mankind ... in the last resort depend on the relations between the parts being governed by the striving for the better satisfaction of their material needs.... it is the market order which makes peaceful reconciliation of the divergent purposes possible - and possible by a process which redounds to the benefit of all. The interdependence of all men, which is now in everybody's mouth and which tends to make all mankind One World, not only is the effect of the market order but could not have been brought about by any other means. ... the degree to which we can participate in the aesthetic or moral strivings of men in other parts of the world we owe to the economic nexus.

Our economic relations, Hayek explained, are critical for the development and maintenance of our social relations, especially when our relations are across social distances.

Through their buying, selling, managing, training, coworking, and simple conversation, market participants develop personal ties with one another, which can develop into commercial friendships. A "commercial friendship" is a term that was coined by Price and Arnould (1999: 50) to denote a relationship that, while founded in a business or economic context, involves "affection, intimacy, social support, loyalty, and reciprocal gift giving," which are typically attributes that are associated with non-market, social contexts. When commercial friendships do spring from market relationships between, say, co-workers, supervisors and their employees, or service providers and their customers, they can be characterized by commitment, trust, communication, closeness, solidarity, and personal loyalty, each varying depending upon the unique characteristics of the context within which the commercial friends are interacting (see e.g., Bove \& Johnson, 2000, 2006; Gummesson, 1991; Hausman, 2001; Arnold et al., 2011).

Friendships that are developed and maintained in markets are quite common. In a nationally representative study, Thomas (2019: 822) "presents results from the first U.S. survey with data on how respondents met their friends, specifically the two nonfamily friends they most often socialize with." According to Thomas (ibid.: 830),

The most common sources of new friendships are very distinct by age: Educational settings are the biggest source in early life, workplace-formed friendships predominate in the middle stages, and brokerage through neighboring (as neighbors or introduced by neighbors) is most common in the later stages of life. The formally organized settings of education and work are the most exceptionally life stage dependent, brokering almost no friendships outside of their dominant stages.

Arguably, some of these common contexts for friendship development can be regarded as commercial spaces. They are commercial spaces because they are 
sites where commerce, that is the activities related to buying and selling, take place. Think here of stores, gyms, hair salons and barbers, restaurants and pubs, factories, offices, and other workspaces. Think also of internet-based social networking communities. Think here of also educational settings like public and private universities and private K-12 schools where students pay tuition as well as summer camps, ballet classes, and music lessons where fees are charged. While the degree to which people in these contexts orient their actions toward purely economic goals varies, there tends to be at least some dependence on market exchange for goods and services that support the goals of the actors within these settings.

\subsection{Markets can facilitate the formation of friendships}

An important feature of markets, one which allows for the development and maintenance of commercial friendships, is the provision of opportunities and reasons for individuals to interact with family, friends, acquaintances, and even strangers. Workplaces are sites where individuals interact frequently with others who they might not otherwise have occasion to know. Restaurants, bars, movie theaters, concert venues, and other destinations provide social spaces for old friends to meet, new acquaintances to interact, and strangers to share meaningful experiences with one another. As Storr (2010: 204) puts it, individuals experience the market "as a social space where social content often overlays economic relations and where social friendships are developed and maintained." That is, like other social settings, markets provide the context within which friendships emerge. This notion is well put by Allan (1998: 688-689), who notes that,

the character of friendship (and other informal) solidarities are patterned by the broader features of people's social and economic location. In this regard, it is inappropriate to conceptualize friendship as a 'natural' or 'pure' relationship, that is as one based solely upon individual choice, feelings and commitment. Rather its form and content are inevitably influenced by the circumstances - or contexts - under which it is constructed.

Markets are especially conducive for the creation of "a more secure matrix for civic and personal friendship" (Badhwar, 2008: 301). Since successful market interactions depend upon trust, markets place individuals in situations where they can observe the trustworthiness and character of others (Storr \& Choi, 2019). While friendships are dependent upon the choices of potential friends, the context within which friendships are formed influences the nature and quality of their relationships.

In addition to providing opportunities or reasons to spend time together, another important way in which a market context influences the development of friendships is by allowing for the accomplishment of tasks around which individuals can personally connect with one another. In highlighting the influence that social context plays in the development of friendships, Feld $(1981,1982,1984)$ coined the term "focus of activity," which is a "social, psychological, legal, or physical entity around which joint activities are organized" (Feld, 1981: 1016). While foci of activity can take 
various forms, such as families, associations, neighborhoods, departments, firms, teams, and clubs, they "all have the common effect of bringing a relatively limited set of individuals together in repeated interactions in and around the focused activity" (Feld \& Carter, 1998: 136). Moreover, each friendship that is formed around a focus of activity "is embedded within a relatively dense web of other relationships (some friendships and some not) that are derived from the same focus of activity" (ibid.). This social embeddedness can influence the shared norms and sanction capabilities that individuals take into consideration in their individual plans for action, which in turn, influences the constitution of the shared meanings that others give to certain types of behavior.

Market settings such as workplaces and commercial establishments where people socialize are foci of activity. For example, although workers are generally oriented towards the accomplishment of some goal in their place of work, such as finishing their projects on time, making a good reputation for themselves, or accomplishing their shared mission, its accomplishment requires varying degrees of interaction with other workers in a concerted, team effort. This repeated, social interaction tends toward the development of personal relationships among the workers, regardless of whether a friendship is intentionally pursued by them. In their survey of Americans with full time jobs, researchers at Olivet Nazarene University (2020) found that $82 \%$ of respondents reported having at least one friend at their workplace, while $29 \%$ reported having at least one best friend. Through the unfolding of the social process required to accomplish an organization's shared goal, the workplace is constituted as the "focus of activity," the foundation upon which personal relationships within the workplace are embedded. Although this is often an unintended or emergent outcome that develops through time as former strangers (new workers) grow into acquaintances or close friends through repeated interaction and routine cooperation, the relationships are nonetheless meaningful even if the individuals regard them as less important than their existing ties with close friends or family developed in other social contexts (Feld \& Carter, 1998). While many, if not most, of the interactions and relationships "that develop around a foci of activity do not become friendships...most friendships do originate in one focus of activity or another" (ibid.: 137). This is not to suggest that markets are the only social arena where meaningful social bonds can be formed or that social bonds formed in markets are as significant as, or more significant than, relationships formed in other settings. It is simply to recognize that economically grounded relationships are not inherently less meaningful and may very well develop into close, personal friendships.

Another common focus of activity in markets is a buyer-seller relationship, such as a supplier-retailer, salesperson-customer, or service provider-client relationship. "In a service setting," Jones et al. (2008: 475) explain, "consumers can become committed to two different entities: the service company and the individual employee with whom the consumer interacts." As Jones et al. (ibid.) elaborate, "the service employee may occupy two different exchange-based roles, one of economic exchange (i.e., the provision of a service) and/or one of social exchange (i.e., friendship)." A friendship can spring from consumers and service employees entering repeated social exchanges with each other. This is essentially "another layer of the relationship between service consumer and employee or organization ... [that] 
serves to enhance commitment to the economic relationship ... by adding another psychological force to compel maintaining the relationship" (ibid.: 477). Higher levels of friendship or personal commitment can be a consequence of the customer experiencing "satisfactory social exchange with the service employee" which can subsequently "result in higher levels of employee commitment as it is transferred over to the economic relationship" (ibid.: 476). Therefore, in some instances, commercial friendships can contribute to the trust and reciprocity that friends experience in their economic exchanges with one another.

The qualities of buyer-seller relationships in markets are also explored by Homburg et al. (2011) who conduct "a cross-industry survey of 56 sales managers, 195 sales representatives, and 538 customers" (795). While the authors are primarily seeking an understanding of the determinants of "customer loyalty" to a good or service provider, they nonetheless offer valuable insights into the different types of relationships that form between buyers and sellers. Like Jones et al. (2008), Homburg et al. (2011: 805) found that "salespeople often play two roles in interactions with customers: the role of a businessperson and the role of a friend," which are not mutually exclusive in that salespeople can occupy multiple roles at once (also see Heide \& Wathne, 2006). While the outcome of such relationships depends upon the choices of the actors and the environment within which they are forming their friendships, friendships certainly do form between not only workers within the same firm or department but also between workers and their customers. In a similar study, Yim et al. (2008) examine how the personal relationships developed between customers of fast food restaurants and hair salons influence the customers' loyalty to the businesses. They surveyed 360 adults from Hong Kong who "had visited a fast-food restaurant and hair salon at least once in the prior six and nine months" (ibid.: 748). They found that.

service quality perceptions and customer satisfaction built through product and service experience, in parallel to the personal relationship developed through social rapport with staff, significantly contribute to the development of trust, which has a significant impact on customer loyalty (and share of purchase)" (ibid.: 750).

While the goal of their study was also to understand the determinants of customer loyalty, Yim et al.'s (ibid.) findings suggest that commercial friendships are very much dependent upon the development of social rapport, trust, and loyalty between the exchange partners.

Yim et al. (ibid.) also present an insightful continuum on which different foci of activity between buyers and sellers are listed, depending upon how conducive the activities are for the development of commercial friendships. Since fast food restaurants are more "transactional," in that they rely less on personal connection and intimacy, and hair salons are more "relational," in that they rely more on personal connection and intimacy, these two business types resemble two ends of a "transactional-relational" continuum. In this sense, the relationship between a hair stylist and a repeat customer tends to resemble the relationship that develops between, say, financial advisors and their clients or real estate agents and homebuyers. Whereas the more "transactional" relationship between a cashier and a hungry customer 
tends to resemble the relationship between a retail sales associate and a shopper or a movie ticketer and a movie-going couple. Moreover, a "transactional" exchange tends to be a one-off encounter whereas a more "relational" exchange tends to be part of an ongoing relationship that may last for weeks, months, or even years. This is not meant to imply that commercial friendships cannot develop from relationships that are less "relational" and more "transactional." These ideal types are only meant to help illustrate the different forms that relationships among buyers and sellers can take. They also suggest that some commercial contexts can be more conducive to the development of friendships than others.

Third, because markets function as social spaces for shared, meaningful experiences and the accomplishment of foci of activities around which to connect, they act as spaces within which weak ties can develop into strong (close) ties. Granovetter's (1973, 1983) work on "the strength of weak ties" points to the importance of weak ties in facilitating the discussion and the transfer of information between different social groups. In discussing how to understand the strength of dyadic ties, however, he stressed the importance of the frequency of interaction. Strong ties, for Granovetter (1973), need a high frequency of interaction to be developed. While it is obvious that markets allow for a wide range of low-frequency and one-off interactions, markets also allow for and encourage repeated interactions, personal exchanges, and shared experiences, and as such they can also be important spaces for strong ties to be cultivated (from weak ties) and maintained. Again, we are not claiming that these relationships would not form without markets, nor are we claiming that marketbased relationships are superior to non-market-based relationships. Rather, we are arguing that markets provide the ability for individuals to interact with others, and the frequency of such interactions, in part, determines the strength of a relationship. Next, we examine how virtual interactions often cannot replicate the face-to-face interactions that frequently take place in market spaces.

\subsection{Virtual interaction is an imperfect substitute for face-to-face interaction}

While remote work, online shopping, social media, and other types of virtual interactions are valuable innovations within markets, they do not easily replicate the in-person commerce and social exchange that markets typically facilitate. In other words, virtual market alternatives are imperfect substitutes for personal interactions when it comes to their facilitating the strengthening of dyadic ties, even though such mediated connections might be valuable complements or substitutes to social interaction for some people in certain contexts.

Take, for example, the fact that most romantic couples have tended to "meet" online in recent years. In their study of the common sources of romantic relationships, Rosenfeld et al. (2019: 17,753) relied on a nationally representative survey of heterosexual, U.S. adults and found that "meeting online has displaced friends as the main way heterosexual couples in the United States meet. Traditional ways of meeting partners (through family, in church, in the neighborhood) have all been declining since World War II. Meeting through friends has been in decline since 
roughly 1995." And by 2017 they found that $39 \%$ of adults reported having met their significant other online (ibid.), ${ }^{2}$ while "meeting through phone apps was responsible for at least half of the growth in meeting online from 2010 to 2017" (ibid.: 17,754). What is important for our purposes, however, is the complementary role that markets play for virtual interactions by providing spaces along with goods and services that require face-to-face interaction between couples. Offering evidence in support of this contention, Rosenfeld et al. (ibid.: 17,755) found a "post-2010 rise in meeting through bars and restaurants for heterosexual couples," which they claim, "is due entirely to couples who met online and subsequently had a first in-person meeting at a bar or restaurant or other establishment where people gather and socialize." Specifically, by 2017 they found that $27 \%$ of couples had a first in-person meeting at a bar or restaurant, most of whom after first "meeting" online (ibid.). Of course, the online spaces are themselves commercial settings. These findings highlight the complementary role that in-person market venues, like bars and restaurants, serve in providing spaces for face-to-face interaction.

This phenomenon in which new technologies serve a complementary role for either older technologies or in-person interaction is touched on by Lavoie (2017). He explains why new technologies (or "media") which serve a communicative function, such as letters, word documents, emails, texts, phone calls, or phone apps, do not typically fully displace older types of media or in-person interaction (ibid.). Physical letters still serve a function, for example, despite the advent of email, phone calls still serve a function despite the advent of text and video calls, and restaurants and bars still serve a social function despite the advent of social media and dating apps. Rather than dating apps fully displacing the function that bars, clubs, or restaurants, serve for prospective daters, there are still advantages to in-person interaction in the commercial spaces. For many prospective daters, the advantage is not so much the in-person commercial space's role as an initial screening venue within which people hope to meet their future partner, but as a space wherein people who previously met online can interact, faceto-face. And this interaction is often necessary for the development and maintenance of not only romantic relationships but close friendships. The advantage of the online dating app, on the other hand, tends to be serving as an intermediary social network that can be more extensive than friends and family, and serving as a screening device that can be more effective, less costly, and less dangerous than in-person, first dates that were arranged prior to any virtual, social interaction. As Rosenfeld et al. (2019: 17,754) put it, "the online precursor to face-to-face meeting inserts a layer of physical distance that can have benefits for safety." For some, the internet makes family and friends no longer comparatively advantaged sources for screening potential friends or romantic partners. And as Rosenfeld et al.'s (2019) data demonstrate, the internet has proven to be a more effective means of serving this preliminary function for some individuals to expand their social networks or meet their spouse. But, even when online settings serve an initial screening function, developing personal relationships also requires in-person

\footnotetext{
${ }^{2}$ There were 2,495 responses in HCMST 2009 and an additional 2,997 in HCMST 2017.
} 
market settings. Two responses from the 2017 survey, referenced by Rosenfeld et al. (ibid.: 17,756), reflect this interdependent relationship between online platforms and in-person commercial spaces,

We found each other through [dating site]. We met in person at a local grocery store. We then proceeded to hang out with each other every single day for the next few months;

and,

We met online. We had drinks one night and were friends for a while then got into a serious relationship.

These responses point to the complementary function that in-person commercial spaces serve in providing individuals with venues to interact in and activities around which they can develop their relationships.

The findings of Rosenfeld et al. (2019) are supported by a recent Pew Research Center (2020: 3) survey of 4,860 U.S. adults conducted in October 2019, wherein $23 \%$ reported having "gone on a date with someone they first met through a dating website." Specifically, the survey revealed that " $39 \%$ of online daters - and $12 \%$ of Americans overall [among those surveyed] - have married or been in a committed relationship with someone they first met through a dating site or app" (ibid.: 16). In short, communication technology, like the telephone or the internet, need not fully displace existing face-to-face interactions, they simply reinforce those interactions while serving as a complementary means through which individuals can start or develop their relationships.

The scholarly literature within psychology and communication studies has found that virtual interactions are substitutes but are imperfect substitutes for face-toface interaction. What is often referred to as computer-mediated, virtual, or online communication by psychologists and communication scholars is typically juxtaposed against face-to-face interactions when analyzing the consequences of a growing share of people, throughout the world, using the internet to communicate with others. Empirical work in developmental psychology, for example, has found that computer-mediated communication between adolescent friends does not fully displace face-to-face interaction, it simply supplements and enhances these personal encounters (Valkenburg \& Peter, 2011; Dienlin et al., 2017; Manago et al., 2020). Although the ability to engage in "digitally mediated social relationships" serves a complementary role in maintaining our offline friendships - which is especially salient when our friends and family are physically distanced from one another - such mediated interactions cannot fully replicate the experiences of unmediated, faceto-face conversation and interpersonal exchange (Chambers, 2013). While virtual media allow for the expansion of social networks into spaces that would otherwise be inaccessible (Best \& Krueger, 2006; Wellman, 1997), "the reduction of social cues [that virtual communication cannot always avoid] makes it far more difficult to develop the intimacy and confidence necessary to deepen relationships" (Best \& Krueger, 2006: 397). Because of these qualitative differences between virtual and in-person communication, the internet tends to be a more suitable platform for the 
development of weak ties rather than strong (close) ties (Bargh \& McKenna, 2004; Blanchard \& Horan, 1998; Haythornthwaite, 2002).

We are not implying that internet usage and online communication between already existing friends somehow damages or is antagonistic to their relationships. In fact, even weak ties could be maintained online and thus online be substitutes for in-person weak ties, especially during a pandemic. Rather, what we are contending is that in-person connections cannot be fully replicated on a virtual platform, at least not in the long run (see Miguel, 2018). Multiple mediums through which individuals connect are valuable means to maintain and develop relationships, and new relationships can, and often do, spring from online websites and phone apps. But the fact that personal relationships start online does not imply that they will also be developed or even maintained on the same virtual medium, without the assistance of unmediated interaction. Rarely do such online relationships develop into close friendships, and when they do, they generally require in-person activities, parties, dates, or some other form of personal interaction to transition into a close friendship.

Related to this discussion of virtual interaction is a concept known as "impression management" - the process by which individuals attempt to influence the perceptions they give to people with whom they are interacting. Communicators do this by seeking to control the information they reveal about themselves through their spoken or written words or non-verbal social cues (Goffman, 1959; Walther, 1996). As media have become increasingly virtual, impression management has taken on various forms. Mediated forms of communication that are asynchronous afford communicators opportunities that would otherwise be unavailable in synchronous or face-to-face interactions, because with asynchronous mediums the communicators are released from geographic and temporal constraints and can review and edit their messages before they are sent. Whereas with synchronous media, like live phone or video calls, although individuals might be released from geographic constraints, they do not necessarily have the same opportunities in terms of their ability to revise, edit, and review their messages before they are released to their receiving audience. This is especially salient on video-conference platforms, like Zoom or Skype, where the communicators are interacting with one another in real-time (Bailenson, 2021). These platforms have advantages over other media vis-à-vis the communication of social cues but disadvantages relative to in-person face-to-face communication. Overall, depending upon the medium's capacity for the communication of social cues and its capacity for synchronous or asynchronous communication, it can have differential effects on how people perceive those whom they are interacting with and the overall quality of their interactions, effects that differ from what would otherwise emerge in face-to-face interaction (ibid.).

Regardless of whether virtual interactions are asynchronous or synchronous, they are still reduced-cue social contexts when compared to face-to-face communication and relationship development. This is not meant to imply that mediated forms of communication in virtual contexts do not serve a valuable function. What it does suggest, however, is that face-to-face interaction is better suited than even the new communicative media at allowing for the development of close, personal friendships in commercial spaces through simple conversation, activities, and shared experiences. 


\subsection{In summary}

To summarize, markets (1) give individuals a reason to spend time together and (2) provide tasks around which people connect. As a result, (3) they allow for the strengthening of weak ties into strong ties. Additionally, market technology, like video calls, texting, and other substitutes to in-person interaction provide an imperfect alternative to face-to-face interactions. While technology can help form or maintain ties, certain aspects of in-person, face-to-face interaction are necessarily lost on such alternative platforms.

Next, in Section 3, we examine primary and secondary data based on survey responses and popular and academic articles regarding the development and maintenance of commercial friendships and acquaintances during the COVID-19 pandemic. We argue that the pandemic has indeed disrupted such commercial relationships, consequently contributing to social losses and increased loneliness.

\section{COVID-19 as a disruptor of commercial friendships}

The COVID-19 pandemic has arguably been a large disruptor of commercial friendships. We propose that there are four main disruptors of commercial friendships during pandemics, and we specifically draw upon evidence from the COVID-19 pandemic. First, pandemics create more anonymity due to the increase in physical distancing and virtual transactions. Second, the social and electronic capabilities available to switch from in-person engagement to online engagement are not perfect substitutes for face-to-face interactions. Third, our social networks effectively shrink during pandemics, leading to less interaction with our weak ties (in markets) and more interaction with our close, familial ties. Last, pandemics lead to lower capacity-limits in commercial settings like bars, sporting arenas and concert venues, limiting social meetings. In this section, we analyze each one of these disruptors in light of evidence from COVID-19.

\subsection{Increased market anonymity due to COVID-19}

Pandemics, like COVID-19, and pandemic-related policies push us into more anonymous, less personalized market interactions, in which face-to-face interactions are replaced with virtually mediated forms of social interaction and economic exchange, such as online shopping, contactless deliveries, and video conference calls. In the case of COVID-19, the most obvious reason for such outcomes stems from the health risks associated with face-to-face interactions. In response to these risks, government policies effectively shut-down or decreased the capacity of most market-created meeting spaces. Workplaces moved online, bars and gyms closed, social congregations halted, schools went largely virtual (with the remaining in-person students physically distanced), and other in-person social spaces were legally prohibited from opening. On top of that, 
government-mandated and voluntary mask wearing tended to increase the level of anonymity or hamper their ability to convey non-verbal social cues during people's relatively limited in-person interactions in commercial spaces. The advent of public mask wearing made the recognition of and interaction with weak ties, including acquaintances and new friends, even more infrequent.

Consider the over 7.7 million people who lost their jobs due to COVID-19 (Woodbury \& Fronstin, 2020), and the estimated $42 \%$ of the workforce currently working from home (Wong, 2020). Yelp found that there were nearly 100,000 business establishments in the US that temporarily shut down due to COVID-19 and are now permanently out of business (Sraders \& Lambert, 2020). According to Yelp, that is around $60 \%$ of the businesses that originally had only temporarily shut down - meaning hundreds of thousands of businesses temporarily closed throughout the pandemic (Sundaram, 2020). Even businesses that remained open shifted to more anonymous practices, such as curbside delivery, in-store pickup (mitigating the need to shop in-store), and most anonymous of all, 'leave at front door' options, where no social interaction occurs. Retail stores opted for curbside delivery, and many restaurants only opted for curbside delivery or home delivery to keep people out of establishments, especially in states where restaurants were closed.

There have been social consequences because of the COVID-19 online shopping, contactless delivery, work-from-home reality. According to a recent survey, nearly $70 \%$ of American workers say, "the coronavirus pandemic is the most stressful time of their professional career," while $88 \%$ "of workers reported experiencing moderate to extreme stress over [the first 4-6 weeks of the COVID-19 pandemic]" (Human Resource Executive, 2020). The Martec Group conducted a similar survey (Laker, 2020) and found that "[j] ob satisfaction, job motivation, and company satisfaction were also negatively affected" by working from home. Indeed, 59\% of employees surveyed dislike working from home, while $42 \%$ of employees who switched to working from home due to the pandemic reported increased stress levels (ibid). Another survey of 4,000 remote workers found that many simply miss the office for its social aspect with $49 \%$ reporting they "miss seeing their colleagues... 14\% saying they miss water cooler chats, and 11\% reporting they were lonely" (Pelta, 2020). Moreover, " $20 \%$ of workers say they find it difficult to 'unplug' when they work from home" (ibid). It is worth noting that even if employees believe working from home is the 'right' or socially conscious decision, they can still greatly miss out on these social aspects.

A recent Gallup (2021) survey also found that working from home tended to be associated with higher levels of "worry" and "stress" among workers. In March of 2020, for example, among the remote workers surveyed, 63\% reported feeling "worried" while $67 \%$ reported feeling "stressed." This was $10 \%$ and $7 \%$ higher than the levels of worry and stress reported by non-remote workers (ibid.). And for each of the remaining months of 2020, an average of about $10 \%$ and $8 \%$ more remote workers reported feeling "worried" and "stressed" relative to non-remote workers (ibid.). Although not speaking directly to the importance of workplace friendships and acquaintances, the absence of these associations arguably do contributes to increased worry and stress. 
Our survey found that before the pandemic, just over one fifth of people socially interacted daily with their work colleagues. During the COVID-19 pandemic, however, just under $12 \%$ of people socialized with work colleagues daily, marking a significant decrease from before the pandemic. Moreover, roughly 25\% of respondents said they felt less connected with work colleagues during the pandemic as compared to before. When asked why they feel less connected many cited not seeing work colleagues as one of the main reasons. One respondent simply said, "I work from home now so i dont [sic] see them every day." Another respondent elaborated further: "I do not see people casually in the same way I did before the pandemic. Time with friends, coworkers, and acquaintances was often a mix of planned and unplanned time together, most often physically in the same place." Yet another respondent discussed how they are "working from home now and barely see anyone." Most directly supporting the argument that people are missing out on market friendships and acquaintances, one respondent said that they feel "less connected to colleagues due to working from home." Workplace closures and remote workplaces leave employees lacking the social connections that they were used to enjoying. Without such face-to-face interactions, employees feel they are missing out on meaningful experiences.

While there may be good reason for many of the practices outlined above, particularly reasons aimed at reducing transmission of the virus, hospitalizations, and deaths, they all largely increase anonymity within the market, decreasing the likelihood that commercial relations will develop into friendships.

\subsection{Virtual interactions are imperfect substitutes for face-to-face interactions}

Markets offer various tools that allow individuals to make and even maintain social connections even when they are physically separated. For instance, cell phones and computers are all relatively new and have been brought about due to dynamic market processes and innovation. Similarly, workplaces can leverage virtual platforms and friends can stay close with messaging and video chatting. However, these tools are imperfect substitutes for face-to-face, market interactions. There is, for instance, a large and growing literature analyzing the negative effects from a work-from-home culture. First, working from home blurs the boundary between home and work, and can create an "always-on work culture" (Derks et al,. 2016) that demands constant connectivity and responsiveness (Matusik \& Mickel, 2011). Moreover, there are often distractions in the home environment from family members, deliveries, and so forth (Allen et al,. 2015). Ashforth et al. (2000) find that the proximity of home and work is emotionally fatiguing and leads to negative emotions.

While there are many virtual alternatives to activities like work and leisure, they do not easily replicate the shared, personal experiences that often occur in real world markets. In many cases, virtual alternatives, like video conference calls, might be unintendedly "neutralizing the social aspect of [work]" (Mo, 2020). According to one tech marketer impacted by the pandemic in the San Francisco Bay Area,

A lot of my work ... is sending out emails, writing up docs, and there's nothing glamorous or particularly exciting about these individual tasks that make 
up my day... What makes it a lot more enjoyable is being able to hang out with people ... as I'm firing off these emails (cited in Mo, 2020)

One of the biggest disadvantages of online formats is their inability to replicate 'water-cooler conversations,' which are impromptu, casual discussions between co-workers about non-work related topics. But when workers are without "shared spaces and rituals, colleagues now have to be proactive to maintain relationships that once thrived on convenience" (ibid.). Many studies also discuss the necessity of casual conversations and suggest that they may unintendedly improve business (Sander et al,. 2019). Such conversations also improve our mental well-being, with non-contrived social interactions said to improve mental health (see Umberson \& Montez, 2010 for a literature overview). ${ }^{3}$

According to Sander and Bauman (2020), one of the major reasons Zoom calls are so draining (known as 'Zoom fatigue') is due to the lack of water-cooler conversations. They discuss how "[i]n person, we often meet people on the way to a meeting to catch up on issues or discuss our views before going in" (ibid). Now, however, individuals are unable to have quick, non-contrived conversations that, for many, can be cathartic or at least enjoyable experiences that offer some sense of social interaction. The nature of online meetings creates a contrived, less sociable environment because participants are immediately in 'meeting mode' upon joining (ibid.). There is rarely a segment of time prior to the meeting to naturally chat and catch up on non-work-related topics (ibid.). And even if such social time is permitted, it presents itself as deliberately contrived rather than an organic, spontaneous encounter. Due to "[t]he absence of casual hallway chats and long lunch breaks... the pandemic could potentially make workers feel more isolated" (Mo, 2020).

Considering the prevalence of Zoom usage during the pandemic, ${ }^{4}$ Bailenson (2021) offers several explanations for the associated fatigue, one of which is pertinent to the focus of this paper: "cognitive load." Bailenson (ibid.: 3-4) explains why Zoom, and videoconferencing media in general, tend to require that users take on a higher cognitive load as they send and receive non-verbal social cues over the virtual platform, compared to in-person interactions. In typical face-toface interactions, non-verbal communication flows "naturally" (ibid.: 3). That is, we tend to be only subsidiarily or "unconsciously" aware of our "own gestures and other nonverbal cues" and the cues we are receiving from our fellow conversers (ibid.). In typical Zoom interactions, however, we tend to exert more mental effort to both "send" and "receive" non-verbal cues (ibid.). Some examples of the conscious monitoring of, and the intentional generation and "sending" of, nonverbal cues over Zoom are the "centering of oneself in the camera's field of view, nodding in an exaggerated way for a few extra seconds to signal agreement, or looking directly into the camera (as opposed to the faces on the screen) to try and make direct eye contact when speaking" (ibid.). When we "receive" social cues,

\footnotetext{
${ }^{3}$ Not only are social relationships said to improve mental well-being, but they also are found to improve physical health and extend life expectancy (see House et al., 1988).

4 Zoom went from having about 10 million users in December 2019 to over 300 million users by June 2020 (Iqbal, 2020; cited in Bailenson, 2021: 1).
} 
such as head, facial, or eye movements, in our face-to-face interactions, they typically help signify when it is our turn to speak or they reveal whether our audience understands, agrees, or disagrees with us. In Zoom interactions, however, these cues can become more easily detached from the sender's intentions. In this sense, Bailenson (ibid.: 3) notes, the cues can become "perceptually realistic, but not socially realistic" (ibid.). In other words, the cues that are received "are not tied to the intention of the person making the gesture" - there is a disconnect between the intended meaning of the cue-sender and the meaning that is ascribed by the cue-receiver(s), a meaning which the receiver(s), for example, may tie to the topic of the Zoom conversation even though the sender was simply responding to some unrelated, one-off encounter that is only perceptually visible from his perspective, such as a new email or message (ibid.).

In addition to COVID-19's impact on places of work and the relationships that develop at work, it has also impacted the learning and socialization abilities of university students, many of whom returned to campus virtually, largely participating in online classes from their home or dorm rooms. University students have experienced major disruptions in what was once an age-old, traditional journey of learning and socializing in groups with teachers and peers. We consider universities as part of the market because (1) virtually everyone at a university is either being paid to be there or paying at least some nominal fee to be there and (2) universities are a type of meeting ground brought about by the market, where colleagues and students can socially interact with one another and develop meaningful social bonds. In their study of Swiss university students impacted by COVID-19, Elmer et al. (2020) found that students had negative mental health trajectories that were higher than before the onset of the pandemic. This is largely attributable to the reduced prevalence of student study groups and their transition to online, virtual platforms. In addition, more students began studying alone, thus losing a core element of university social networks (ibid.). Such study groups are well-suited for socialization, friendship, relationship building, and the making of meaningful connections beyond the classroom.

In general, Elmer et al. (ibid.) found that students on campus have a much higher risk of social isolation and adverse psychological effects due to closures and distancing measures enacted in reaction to COVID-19. Further evidence of the psychological effects of the pandemic is found in Browning et al.'s (2021) cross-sectional study, in Spring of 2020, of 14,174 college students "from representative and targeted samples at seven large, state universities" throughout the U.S. While "all students surveyed reported being negatively affected by the pandemic in some way...59\% of respondents experienced high levels of psychological impact" (Browning et al., 2021: 19). The most common self-reported changes among the students "were increased lack of motivation, anxiety, stress, and isolation" (ibid.: 8). As one student put it,

I'm normally extremely motivated, and I've never struggled with depression, but have recently felt very sluggish and melancholy (ibid.).

According to another student, 
I feel trapped. I don't have anywhere I need to go since I can't socialize, and I have schoolwork. But yet I still feel trapped due to actual restrictions and suggestions (ibid.).

While distanced and home learning can substitute for or complement in-person learning, the substitute is imperfect and may only serve a complementary function. Indeed, with the general shutdowns of in-person marketplaces and the rise of virtual substitutes, much of what we would consider market meeting grounds are no longer facilitating commercial friendships - restaurants, coffee shops, bars, gyms, grocery stores and more are now either virtual, closed, or do not perpetuate norms of either meeting new people or developing existing relationships.For example, it is now more unlikely that one would stop to chat to a friend or acquaintance in the grocery store, or chat with their coffee barista. When asked what she missed most during COVID-19, one survey respondent reported that it was having the ability to meet and chat with her friends face-to-face while simply grabbing a cup of coffee or a bite to eat (Carty-Williams, 2020).

\subsection{Close ties over weak ties}

When pandemics occur, for various reasons, we spend more time interacting socially with closer ties and less time interacting socially with weaker ties than before the pandemic. As mentioned earlier, close ties describe closer friends who generally belong to the same social group and typically share similar information and knowledge (Granovetter, 1973, 1983). Weak ties, however, are more distant friends or acquaintances who likely belong to separate social groups. Weak ties, therefore, can bridge an individual to new knowledge, social groups, job connections, and other social interactions and information. To the extent that our commercial friends and acquaintances are weaker ties than, say, our childhood friends or family members, we are more likely to spend less time with them during a pandemic.

Sandstrom and Whillans (2020) discuss how interactions with weak ties have significantly decreased during the COVID-19 pandemic (see also Pitas \& Ehmer, 2020; Walsh, 2020; Mull, 2021). What used to be 11-16 interactions with weak ties on any given day (Sandstrom \& Dunn, 2014) - with baristas, colleagues, classmates, and so forth - has dropped to nearly zero interactions during the height of the pandemic, at least ones that happen in natural, organic ways. Instead, we must now initiate these once organic encounters, which can feel awkward and forced (Sandstrom $\&$ Whillians, 2020). Sandstrom and Dunn (2014) report that when individuals were asked to 'personalize' a transaction - such as smiling at, making eye contact with, or having a chat with their barista - they felt $17 \%$ happier and more socially connected than those who avoided such interactions. Rodriguez (2020) finds similar results, as he discusses how COVID-19 has disrupted many of the weak ties we form through impromptu conversations with strangers: "individuals we don't know well, if at all... nevertheless contribute to our happiness and sense of belonging." He notes that many of these encounters, "which have largely gone missing with the advent of stayat-home orders and lockdowns," are critical to our well-being since they do not use much of our time, often provide opportunities to be heard and appreciated, typically 
come free of any expectations, and can help us cope with difficult challenges in life (ibid.).

Consider again the case of employees. As evidenced in our survey, one spends much less time with work colleagues during COVID-19 than previously spent. However, if those individuals do not live alone, they are at least working from home with spouses, children, and parents - largely experiencing most socialization with their strong ties, with very few organic, weak tie interactions. Also consider college students, who, as discussed earlier, are facing large restrictions on study groups, social events, and simple conversations. They, too, are now either learning entirely from home, only partially going into school, or attending socially distanced lectures and class sessions where group-work and organic chit-chat is largely vacant. This cuts down on how many weak ties students can form and nurture, and especially reduces the likelihood that weak ties will develop into strong ties. Instead, students are largely developing and maintaining relationships with their familial, closer ties. The issue with spending time with close ties is not inherently bad; however, a loss of weak ties can be quite detrimental for individuals (see Wakefield et al., 2017). ${ }^{5}$

\subsection{Capacity limits on commercial settings}

Pandemics such as COVID-19 limit the capacity of commercial settings to serve as social settings. Shutting down market settings during COVID-19 meant that social interactions also decreased. Many market interactions, workplace interactions, study groups, and so forth, cannot take place if market spaces are shut down or severely limited in capacity. Beginning in March of 2020, when the pandemic took the U.S. by storm, state and city governments across the country had imposed varying capacity restrictions on private and public buildings. Stricter states, like Michigan, had indoor dining banned for over 10 weeks, from mid-November 2020 through the beginning of February 2021. Even other states that had more relaxed restrictions still maintained at least some capacity limits at different times throughout the pandemic. Florida, for instance, had restaurants limited to 50\% capacity - and while that is high relative to other states, it is still a 50\% reduction of typical capacity settings pre-COVID, meaning at least $50 \%$ less gathering in social settings is taking place. According to New York Times data from early February 2021, 15 states were either partially or mostly closed, while the remaining were 'mostly open,' meaning there were still government implemented, capacity limits in public places that were legally allowed to open (The New York Times, 2021b).

Earlier in the pandemic, however, many states had more severe restrictions. Throughout Spring of 2020, 46 states issued stay-at-home orders at some point, three of which had regional stay-at-home orders. Moreover, all 50 states at some point in Spring of 2020 ordered closures of schools and 42 states ordered closures

\footnotetext{
${ }^{5}$ Wakefield et al. (2017) find that regardless of nationality or age, people who were members of groups with weak ties, like sports teams, church groups, and other associations, had an increased sense of meaning and security. And the more groups one was a part of, the better their outcomes were on these measures.
} 
of day care centers. Also, 48 states ordered closures of bars and sit-down restaurants throughout the earlier days of the pandemic. Meanwhile, 41 states closed "nonessential" retail throughout the entirety of the state, while 6 states closed non-essential retail regionally. ${ }^{6}$ Thus, with stay-at-home orders and the closing or limitation of day care centers, restaurants, bars, and non-essential retail throughout large parts of the pandemic, it would seem obvious that meetings within these spaces would also be severely restricted.

Recall, in our nearly a quarter of respondents felt they were less connected to individuals during the pandemic than they were before it. Many explained that the reason they felt less connected was because they no longer see their colleagues and friends in person. While they still used other apps to connect, such as FaceTime, online games, and letters, many described how the connection just wasn't the same as pre-COVID. One survey respondent, answering why they felt less connected to colleagues and friends during the pandemic, described how "[t]he ability to see others in person and have conversations/shared experiences has decreased." This is exactly what we would expect, given that market meeting grounds are restricted while some are altogether closed.

The pandemic has led to many issues, including increased loneliness and the inability to socialize with friends and colleagues in market spaces. The BBC reported that "one in two Australians reported feeling lonely during the first lockdown. In Britain and the US, the ratio was two out of three" (BBC, 2020). One person described the loss associated with friendships throughout the pandemic as quite difficult to come to terms with:

[T]o lose the ability to see the friends that make up the predominant volume of my everyday, face-to-face human interaction has been a challenge. I don't think I'd really appreciated the value of just seeing other faces, grabbing lunch together or...laugh[ing] our way through a film... (IGlobal Staff, 2020).

Indeed, it seems that these connections have not only been widely disrupted by COVID-19, but that individuals have consequently lost something of great value due to the closures and restrictions on market meeting places - that being the human connection.

\section{Conclusion}

Markets provide reasons for individuals to meet with one another and spend some time together. Restaurants and bars provide venues to meet new people, reconnect with old friends, or celebrate with family. And regular trips to the office coffee pot might very well spark an interesting conversation with a new coworker, or perhaps offer a chance to catch up with an old friend. While online shopping and remote

\footnotetext{
${ }^{6}$ See Storr et al. (2021b) for a discussion of the knowledge problems inherent in determining which businesses were truly essential as jurisdictions adopted stay-at-home orders that restricted non-essential activities.
} 
work are certainly valuable products of entrepreneurship in the market process that demonstrate its dynamism and ingenuity, they do not easily replicate the shared, personal experiences that often occur in real world markets.

In this paper, we argue that the COVID-19 pandemic has been a large disruptor of commercial friendships in several fundamental ways. First, pandemics create more anonymity due to the increase in distancing and virtual transactions. Second, the social and electronic capabilities available to switch from in-person engagement to online engagement are not perfect substitutes. Third, our networks shrink during pandemics, thus leading to less interaction with our market-related, weak ties and more with our familial, strong ties. Lastly, pandemics lead to lower capacity-limits in commercial settings, thus limiting social meetings. The pandemic and its related policies have altered and diminished our commercial friendships in large ways, and perhaps in some that are yet to be realized.

Future research can and should examine instances of entrepreneurial action that attempt to fix or mitigate the issue of decreased market friendships. There have certainly been many creative solutions to the COVID-19 pandemic in other ways, such as breweries creating hand sanitizer and individuals 3-D printing ventilator parts. Entrepreneurial acts like engineering enhanced ventilation systems, which allow for higher capacity limits, is an example of where entrepreneurship can mitigate the effects of pandemics on commercial friendships, and future research can explore such entrepreneurial discoveries. Future research could also examine the societywide costs on productivity due to reduced collaboration in-person, with more 'Zoom fatigue' and less organic, non-contrived conversations. Surely this not only has effects on mental health and friendships, but workforce effects as well.

While pandemics can be an impetus for certain market innovations and social capital generation, ${ }^{7}$ entrepreneurship and social capital are nonetheless reliant upon weak ties that are formed - and potentially made stronger - in face-to-face interactions between, say, service providers and their clients, investors and startup founders, managers and their staff, co-workers, or neighbors. And if commercial spaces are closed or limited during a pandemic, we would expect to see entrepreneurial responses to pandemics be less adaptive than they otherwise would be as individuals would be hindered in their attempts to mitigate the pandemic's social consequences. That said, the longer the pandemic conditions persist, the more we should expect to see certain market innovations and social capital generation despite the closures and limitations of commercial spaces - where in-person exchange would occur - as there is often a resilience of human ingenuity and social coordination in the face of adversity, as is often seen in disaster scenarios (N. Storr et al., 2015a, b). Moreover, if we accept that spending time and resources to socially interact with friends and family in commercial spaces are indeed valuable to consumers, then we would expect to see entrepreneurs - if they are free to do so - responding to profit opportunities to provide safe venues and activities for people to engage in.

But limits on in-person activities, and the closure of commercial spaces where face-to-face interaction would otherwise occur, can indeed inhibit people's

\footnotetext{
${ }^{7}$ See Storr et al. (2021a) for a discussion of the social capital that has generated in response to COVID19.
} 
abilities to socialize, cooperate, and share meaningful experiences with one another. If friendships develop in commercial contexts - where trust and reciprocity are on display - then placing physical limits on commercial exchange can hinder people's ability to connect with others. This may contribute to social division, as conversations among strangers, the integration of weak ties, and the strengthening of ties would be hindered. Putnam's (2000) "Bowling Alone" concerns become even more prominent in this world. If market spaces are shut down, we could see decaying of friendships and the ability to engage civilly with others, on top of heightened loneliness. Hertz (2021), for instance, has argued that we are already a lonelier society, and that COVID-19 is exacerbating the issue. The limits of market interactions during the pandemic have revealed one of its important but often underappreciated aspects - its capacity for peaceful, extra-economic exchange and the development of meaningful friendships. Consequently, we ought to be cognizant of the damaging effects that can occur when market settings are closed or restricted and should factor these costs into pandemic policies.

\section{Declarations}

Conflicts of interest None.

Data availability N/A

Code availability N/A

\section{References}

Aassve, A., Alfani, G., Gandolfi, F., Le Moglie, F. (2020). Epidemics and trust: The case of the Spanish flu, Working Papers 661, IGIER (Innocenzo Gasparini Institute for Economic Research), Bocconi University.

Allan, G. (1998). Friendship, sociology, and social structure. Journal of Social and Personal Relationships, 15(5), 685-702.

Allen, T. D., Golden, T. D., \& Shockley, K. M. (2015). How effective is telecommuting? Assessing the status of our scientific findings. Psychological Science in the Public Interest, 16(2), 40-68. https:// doi.org/10.1177/1529100615593273

Arnold, S. L., Nguyen, D. T., \& Hartley, N. (2011). Pro bono service sheds new light into commercial friendship. Journal of Strategic Marketing, 19(4), 381-394.

Ashforth, B. E., Kreiner, G. E., \& Fugate, M. (2000). All in a day's work: Boundaries and micro role transitions. Academy of Management Review, 25(3), 472-491. https://doi.org/10.5465/AMR.2000. 3363315

Badhwar, N. K. (2008). Friendship and commercial societies. Politics, Philosophy, and Economics, 7(3), $301-326$.

Bailenson, J. N. (2021). Nonverbal overload: A theoretical argument for the causes of Zoom fatigue. Technology, Mind, and Behavior, 2(1), 1-6.

Bargh, J. A., \& McKenna, K. Y. A. (2004). The internet and social life. Annual Review of Psychology, 55, $573-590$.

BBC. (2020). How lockdowns are changing our friendship groups. https://www.bbc.com/worklife/article/ 20201005-how-covid-19-is-changing-our-social-networks. Accessed 7 December 2020

Best, S. J., \& Krueger, B. S. (2006). Online interactions and social capital: Distinguishing between new and existing ties. Social Science Computer Review, 24(4), 395-410. 
Blanchard, A., \& Horan, T. (1998). Virtual communities and social capital. Social Science Computer Review, 16, 293-307.

Bove, L. L., \& Johnson, L. W. (2000). A customer-service worker relationship model. International Journal of Service Industry Management, 11, 491-511.

Bove, L. L., \& Johnson, L. W. (2006). Customer loyalty to one service worker: Should it be discouraged? International Journal of Research in Marketing, 23, 79-91.

Browning, M. H. E. M., Larson, L. R., Sharaievska, I., Rigolon, A., McAnirlin, O., Mullenbach, L., et al. (2021). Psychological impacts from COVID-19 among university students: Risk factors across seven states in the United States. PLOS ONE, 16(1), e0245327. https://doi.org/10.1371/journal. pone. 0245327

Bueno-Notivol, J., Gracia-García, P., Olaya, B., Lasheras, I., López-Antón, R., \& Santabárbara, J. (2021). Prevalence of depression during the COVID-19 outbreak: A meta-analysis of community-based studies. International Journal of Clinical and Health Psychology, 21(1), 100196. https://doi.org/ 10.1016/j.ijchp.2020.07.007

Bureau of Economic Analysis (BEA). (2020). Gross Domestic Product, 2nd Quarter 2020 (Second Estimate); Corporate Profits, 2nd Quarter 2020 (Preliminary Estimate). Bureau of Economic Analysis.

Carty-Williams, C. (2020). Living alone in lockdown, I miss my friends more than family. The Guardian. https://www.theguardian.com/books/2020/may/23/living-alone-in-lockdown-i-miss-my-frien ds-more-than-family. Accessed 7 December 2020.

Chambers, D. (2013). Social media and personal relationships: Online intimacies and networked friendship. Palgrave Macmillan.

Chamlee-Wright, E. (1997). The cultural foundations of economic development: Urban female entrepreneurship in Ghana. Routledge.

Chamlee-Wright, E. (2010). The cultural and political economy of recovery: Social learning in a postdisaster environment. Routledge.

Chamlee-Wright, E., \& Storr, V. H. (2009). Club goods and post-disaster community return. Rationality and Society, 21(4), 429-458.

Chamlee-Wright, E., \& Storr, V. H. (2014). Commercial relationships and spaces after disaster. Social Science and Public Policy, 51, 656-664.

Congressional Research Service (CRS). (2020). Unemployment rates during the COVID-19 pandemic: Prepared by Gene Falk, Isaac A. Nicchitta, Paul D. Romero, and Emma C. Nyhof (pp. 1-25, Rep.). Congressional Research Service. https://sgp.fas.org/crs/misc/R46554.pdf. Accessed 31 Aug 2021.

Derks, D., Bakker, A. B., Peters, P., \& Van Wingerden, P. (2016). Work-related smartphone use, workfamily conflict and family role performance: The role of segmentation preference. Human Relations, 69(5), 1045-1068. https://doi.org/10.1177/0018726715601890

Dienlin, T., Masur, P. K., \& Trepte, S. (2017). Reinforcement or Displacement? The Reciprocity of FtF, IM, and SNS Communication and Their Effects on Loneliness and Life Satisfaction. Journal of Computer-Mediated Communication, 22(2), 71-87. https://doi.org/10.1111/jcc4.12183

Dong, E, Du, H, Gardner, L. (2021). An interactive web-based dashboard to track COVID-19 in real time. Lancet Infect Dis; published online Feb 19. https://doi.org/10.1016/S1473-3099(20) 30120-1.

Elmer, T., Mepham, K., \& Stadtfeld, C. (2020). Students under lockdown: Comparisons of students' social networks and mental health before and during the COVID-19 crisis in Switzerland. PLoS ONE, 15(7), e0236337. https://doi.org/10.1371/journal.pone.0236337

Feld, S. L. (1981). The focused organization of social ties. American Journal of Sociology, 86(5), 1015-1035.

Feld, S. L. (1982). Structural determinants of similarity among associates. American Sociological Review, 47(6), 797-801.

Feld, S. L. (1984). The structured use of personal associates. Social Forces, 62(3), 640-652.

Feld, S., \& Carter, W. C. (1998). Foci of activity as changing contexts for friendship. In R. G. Adams \& G. Allen (Eds.), Placing friendship in context (pp. 136-152). Cambridge University Press.

Gallup. (2021). The well-being engagement paradox of 2020. https://www.gallup.com/workplace/ 336941/wellbeing-engagement-paradox-2020.aspx. Accessed 8 June 2021.

Goffman, E. (1959). The presentation of self in everyday life. Doubleday Anchor Books.

Granovetter, M. (1973). The strength of weak ties. American Journal of Sociology 78(6):1360-1380. http://www.jstor.org/stable/2776392. 
Granovetter, M. (1983). The strength of weak ties: A network theory revisited. Sociological Theory, 1, 201-233.

Grube, L., \& Storr, V. H. (2018). Embedded entrepreneurs and post-disaster community recovery. Entrepreneurship \& Regional Development, 30(7-8), 800-821.

Gummesson, E. (1991). Service quality, a holistic view. In S. W. Brown, E. Gummesson, B. Edvardsson, \& B. O. Gustavsson (Eds.), Service quality: Multidisciplinary and multinational perspectives (pp. 3-22). Lexington Books.

Haerpfer, C., Inglehart, R., Moreno, A., Welzel, C., Kizilova, K., Diez-Medrano, J., Lagos, M., Norris, P., Ponarin, E., Puranen, B., et al. (eds) (2020), World values survey: Round seven - countrypooled datafile. JD Systems Institute \& WVSA Secretariat. https://doi.org/10.14281/18241.1.

Hausman, A. (2001). Variations in relationship strength and its impact on performance and satisfaction in business relationships. Journal of Business and Industrial Marketing, 16, 600-616.

Hayek, F.A. (1976). Law, legislation and liberty, vol 2: The mirage of social justice. University of Chicago Press

Haythornthwaite, C. (2002). Strong, weak, and latent ties and the impact of new media. The Information Society, 18, 1-17.

Heide, J. B., \& Wathne, K. H. (2006). Friends, businesspeople, and relationship roles: A conceptual framework and a research agenda. Journal of Marketing, 70, 90-103.

Homburg, C., Müller, M., \& Klarmann, M. (2011). When does salespeople's customer orientation lead to customer loyalty? The differential effects of relational and functional customer orientation. Journal of the Academy of Marketing Science, 39, 795-812.

House, J. S., Landis, K. R., \& Umberson, D. (1988). Social relationships and health. Science, 241, $540-545$.

Human Resource Executive. (2020). HRE's number of the day: Coronavirus stress. https://hrexe cutive.com/hres-number-of-the-day-coronavirus-stress/. Accessed 6 March 2021.

Hyland, P., Shevlin, M., McBride, O., Murphy, J., Karatzias, T., Bentall, R., ... Vallières, F. (2020). Anxiety and depression in the Republic of Ireland during the COVID-19 pandemic. https://doi. org/10.31234/osf.io/8yqxr

IGlobal Staff. (2020). Missing a simple cup of tea with friends in lockdown. https://www.iglobalnews. com/icommunity/missing-a-simple-cup-of-tea-with-friends-in-lockdown. Accessed 7 December 2020.

Iqbal, M. (2020). Zoom revenue and usage statistics. Business of Apps. https://www.businessofapps. com/data/zoom-statistics/. Accessed 17 June 2021.

Jones, T., Taylor, S. F., \& Bansal, H. S. (2008). Commitment to a friend, a service provider, or a service company - are they distinctions worth making? Journal of the Academy of Marketing Science, 36(4), 473-487.

Laker, B. (2020). Working from home is disliked by and bad for most employees, say researchers. https://www.forbes.com/sites/benjaminlaker/2020/08/24/working-from-home-is-disliked-byand-bad-for-most-employees/?sh=1eb5072b6734. Accessed 12 December 2020.

Langer, G. (2020). Coronavirus impacts: Disrupted lives, elevated stress, and soaring worry: Poll. https://abcnews.go.com/Politics/coronavirus-impacts-disrupted-lives-elevated-stress-soaringworry/story? id=69812058. Accessed 6 December 2020.

Lavoie, D, (2017), Subjective orientation and objective wealth: entrepreneurship and the convergence of groupware and hypertext capabilities. In: High J (ed) Humane economics: Essays in honor of Don Lavoie, foreword by Solomon Stein \& Stefanie Haeffele-Balch. Mercatus Center.

Makridis, C., \& Hartley, J. (2020). The cost of covid-19: A rough estimate of the 2020 US GDP impact. SSRN Electronic Journal. https://doi.org/10.2139/ssrn.3570731

Manago, A. M., Brown, G., Lawley, K. A., \& Anderson, G. (2020). Adolescents' daily face-to-face and computer-mediated communication: Associations with autonomy and closeness to parents and friends. Developmental Psychology, 56(1), 153-164.

Marwick, A. E. (2013). Status update: Celebrity, publicity, and branding in the social media age. Yale University Press.

Matusik, S. F., \& Mickel, A. E. (2011). Embracing or embattled by converged mobile devices? Users' experiences with a contemporary connectivity technology. Human Relations, 64(8), 1001-1030. https://doi.org/10.1177/0018726711405552

Matzat, U. (2010). Reducing problems of sociability in online communities: Integrating online communication with offline interaction. American Behavioral Scientist, 53(8), 1170-1193. 
Miguel, C. (2018). Personal relationships and intimacy in the age of social media. Palgrave Macmillan.

von Mises, L. ([1949] 2007). Human action: A treatise on economics in 4 vols, Greaves BB (ed). Liberty Fund, Indianapolis.

Mo, N. (2020). The pandemic is changing work relationships. The Atlantic. https://www.theatlantic.com/family/archive/2020/07/what-pandemic-doing-work-friendships/614407/. Accessed 6 March 2021.

Moon, B. (2020). 24 bankruptcy filings chalked up to COVID-19. https://www.kiplinger.com/inves ting/601342/bankruptcy-filings-chalked-up-covid-19-coronavirus. Accessed 6 December 2020.

Mull, A. (2021). The pandemic has erased entire categories of friendship. The Atlantic. https://www. theatlantic.com/health/archive/2021/01/pandemic-goodbye-casual-friends/617839/. Accessed 2 February 2021.

Hertz, N. (2021). The lonely century: how to restore human connection in a world that's pulling apart. Penguin Random House.

Olivet Nazarene University. (2020). Research on friends at work. https://online.olivet.edu/news/resea rch-friends-work. Accessed March 62021.

Pelta, R. (2020). Productivity, work-life balance improves during pandemic. https://www.flexjobs. com/blog/post/survey-productivity-balance-improve-during-pandemic-remote-work/. Accessed 8 December 2020.

Pew Research Center. (2018). Where Americans find meaning in life. https://www.pewforum.org/ 2018/11/20/where-americans-find-meaning-in-life/. Accessed 9 June 2021.

Pew Research Center. (2020). The virtues and downsides of online dating. https://www.pewresearch. org/internet/2020/02/06/the-virtues-and-downsides-of-online-dating/. Accessed 12 June 2021.

Pitas, N., \& Ehmer, C. (2020). Social Capital in the Response to COVID-19. American Journal of Health Promotion, 34(8), 942-944. https://doi.org/10.1177/0890117120924531

Price, L. L., \& Arnould, E. J. (1999). Commercial friendships: Service provider-client relationships in context. Journal of Marketing, 63(4), 38-56.

Putnam, R. (2000). Bowling Alone. Simon \& Schuster.

Rodriguez, J. (2020). The value of talking to strangers - and nodding acquaintances. The Harvard Gazette, Health \& Medicine. https://news.harvard.edu/gazette/story/2020/08/covid-19-is-evapo rating-casual-connections-and-why-thats-bad/. Accessed 6 March 2021.

Rosenfeld, M. J., Thomas, R. J., \& Hausen, S. (2019). Disintermediating your friends: How online dating in the United States displaces other ways of meeting. PNAS, 116(36), 17753-17758.

Sander, L., Bauman, O. (2020). Zoom fatigue is real - here's why video calls are so draining. https:// ideas.ted.com/zoom-fatigue-is-real-heres-why-video-calls-are-so-draining/. Accessed 7 December 2020 .

Sander, E. (L. )J., Caza, A., \& Jordan, P. J. (2019). Psychological perceptions matter: Developing the reactions to the physical work environment scale. Building and Environment, 148, 338-347. https://doi.org/10.1016/j.buildenv.2018.11.020

Sandstrom, G. M., \& Dunn, E. W. (2014). Social interactions and well-being: The surprising power of weak ties. Personality and Social Psychology Bulletin, 40(7), 910-922.

Sandstrom, G., \& Whillans, A. (2020). Why you miss those casual friends so much. https://hbr.org/ 2020/04/why-you-miss-those-casual-friends-so-much. Accessed 2 Feb 2021.

Smith A ([1759] 1976) The theory of moral sentiments. Liberty Fund

Sraders, A., Lambert, L. (2020). Nearly 100,000 establishments that temporarily shutdown are now out of business. https://fortune.com/2020/09/28/covid-buisnesses-shut-down-closed/. Accessed 7 December 2020.

Storr, V. H. (2008). The market as a social space: On the meaningful extraeconomic conversations that can occur in markets. The Review of Austrian Economics, 21, 135-150.

Storr, V. H. (2009). Why the market? Markets as social and moral spaces. Journal of Markets \& Morality, 12(2), 277-296.

Storr, V. H. (2010). The social construction of the market. Soc, 47, 200-206.

Storr, V. H., \& Choi, G. S. (2019). Do markets corrupt our morals? Palgrave Macmillan.

Storr, V. H., \& Stein, S. (2019). Max Weber on the market's impersonality and ethic. Max Weber Studies, 19(1), 43-63.

Storr, N. M., Chamlee-Wright, E., \& Storr, V. H. (2015a). How we came back: Voices from postKatrina New Orleans. George Mason University. 
Storr, V. H., Haeffele-Balch, S., \& Grube, L. E. (2015b). Community revival in the wake of disaster: Lessons in local entrepreneurship. Palgrave Macmillan.

Storr, V. H., Haeffele, S., Grube, L. E., \& Lofthouse, J. K. (2021a). Crisis as a source of social capital: Adaptation and formation of social capital during the COVID-19 pandemic. Cosmos + Taxis, 9(5+6), 94-108.

Storr, V. H., Haeffele-Balch, S., Lofthouse, J., \& Grube, L. E. (2021b). Essential or not? Knowledge problems and COVID-19 stay-at-home orders. Southern Economic Journal, 87, 1229-1249.

Sundaram, A. (2020). Yelp data shows $60 \%$ of business closures due to the coronavirus pandemic are now permanent. https://www.cnbc.com/2020/09/16/yelp-data-shows-60percent-of-busin ess-closures-due-to-the-coronavirus-pandemic-are-now-permanent.html. Accessed 7 December 2020.

The New York Times. (2021a). Coronavirus in the U.S.: Latest Map and Case Count. https://www. nytimes.com/interactive/2021/us/covid-cases.html

The New York Times. (2021b). See coronavirus restrictions and mask mandates for all 50 states. Retrieved February 03, 2021, from https://www.nytimes.com/interactive/2020/us/states-reopenmap-coronavirus.html.

Thomas, R. J. (2019). Sources of friendship and structurally induced homophily across the life course. Sociological Perspectives, 62(6), 822-843.

Umberson, D., \& Montez, J. K. (2010). Social relationships and health: A flashpoint for health policy. Journal of Health and Social Behavior, 51 Suppl(Suppl), S54-S66. https://doi.org/10.1177/ 0022146510383501

Valkenburg, P. M., \& Peter, J. (2011). Online communication among adolescents: An integrated model of its attraction, opportunities, and risks. The Journal of Adolescent Health, 48, 121-127.

Wakefield, J. R. H., Sani, F., Madhok, V., et al. (2017). The relationship between group identification and satisfaction with life in a cross-cultural community sample. Journal of Happiness Studies, $18,785-807$.

Walsh, C, (2020). COVID-19 is evaporating casual connections and why that's bad. https://news.harva rd.edu/gazette/story/2020/08/covid-19-is-evaporating-casual-connections-and-why-thats-bad/. Accessed 2 February 2021.

Walther, J. B. (1996). Computer-mediated communication: Impersonal, interpersonal, and hyperpersonal interaction. Communication Research, 23(1), 3-43.

Wellman, B. (1997). An electronic group is virtually a social network. In S. Kiesler (Ed.), Cultures of the internet (pp. 179-205). Lawrence Erlbaum.

Wong, M. (2020). A snapshot of a new working-from-home economy. https://news.stanford.edu/2020/ 06/29/snapshot-new-working-home-economy/. Accessed 8 December 2020.

Woodbury, S.A., Fronstin, P. (2020). How many Americans have lost jobs with employer health coverage during the pandemic? https://www.commonwealthfund.org/publications/issue-briefs/2020/oct/ how-many-lost-jobs-employer-coverage-pandemic. Accessed 8 December 2020.

Yim, C. K. (B. ), Tse, D. K., \& Chan, K. W. (2008). Strengthening customer loyalty through intimacy and passion: Roles of customer-firm affection and customer-staff relationships in services. Journal of Marketing Research, 45(6), 741-756.

Publisher's note Springer Nature remains neutral with regard to jurisdictional claims in published maps and institutional affiliations. 